\section{Case Reports in Gastroenterology}

Case Rep Gastroenterol 2017;11:29-35

DOI: $10.1159 / 000454710$

Publisned ontine: January 27, 2017 (c) 2017 The Author(s)

Published by S. Karger AG, Basel www.karger.com/crg

This article is licensed under the Creative Commons Attribution-NonCommercial 4.0 International License (CC BY-NC) (http://www.karger.com/Services/OpenAccessLicense). Usage and distribution for commercial purposes requires written permission.

\title{
Successful Treatment of Hepatocellular Carcinoma Complicated by Fanconi Anemia
}

\author{
Koji Takahashi ${ }^{a}$ Eiichiro Suzuki ${ }^{a}$ Masayuki Yokoyama ${ }^{a}$ \\ Masanori Inoue $^{a}$ Toru Wakamatsu ${ }^{a}$ Tomoko Saito $^{a}$ Yuko Kusakabe $^{a}$ \\ Sadahisa Ogasawara ${ }^{a}$ Yoshihiko Ooka $^{a}$ Akinobu Tawada ${ }^{a}$ \\ Yuhei Nagao $^{\mathrm{b}}$ Chiaki Nakaseko $^{\mathrm{b}}$ Tetsuhiro Chiba ${ }^{\mathrm{a}}$ \\ a'Department of Gastroenterology and Nephrology, Graduate School of Medicine, Chiba \\ University, Chiba, Japan; ${ }^{b}$ Department of Hematology, Chiba University Hospital, \\ Chiba, Japan
}

\section{Keywords}

Fanconi anemia $\cdot$ Hepatocellular carcinoma $\cdot$ Transcatheter arterial embolization

\begin{abstract}
A 42-year-old woman with liver tumors was referred to our hospital. Her condition was complicated by Fanconi anemia, and she had undergone total laryngectomy 8 years ago. On admission, contrast-enhanced computed tomography revealed hypervascular tumors in the right hepatic lobe. Ultrasound-guided tumor biopsy revealed that the tumor comprised moderately differentiated hepatocellular carcinoma. Although the patient exhibited preserved liver function (Child-Pugh A), complete blood count revealed severe pancytopenia. Eventually, the tumor was successfully treated by transcatheter arterial embolization (TAE). Both platelet transfusion and systemic administration of antibiotics were performed. She was discharged 35 days after TAE.

(C) 2017 The Author(s)

Published by S. Karger AG, Basel
\end{abstract}




\section{Case Reports in Gastroenterology}

\section{Introduction}

Fanconi anemia (FA) is an inherited aplastic anemia that is characterized by congenital abnormalities such as skeletal defects and hypopigmentation, progressive bone marrow failure, and susceptibility to malignancies [1]. FA is considered to be caused by mutations in genes regulating replication-dependent removal of interstrand DNA crosslinks [2]. Apoptotic induction in hematopoietic stem cells (HSCs) caused by unrepaired DNA damage resulted in depletion of HSCs; this further leads to pancytopenia [3]. It has been shown that $75-90 \%$ of the patients demonstrate pancytopenia. Allogeneic HSC transplantation, which is the only curative modality for bone marrow failure in patients with FA, has been reported to contribute to favorable survival [4].

FA patients frequently develop hematological and nonhematological malignancies [5]. It has been reported that these patients carry a more than 500 -fold higher risk of developing hematological malignancies such as leukemia and myelodysplastic syndrome compared with healthy people. Among solid tumors, the development of head and neck squamous cell carcinoma has been well documented, but the incidence of hepatocellular carcinoma (HCC) appears to be less common [6]. Therefore, the clinical condition and treatment approach for HCC in FA patients remain to be elucidated.

Here, we describe an unusual case of HCC complicated by FA, wherein the patient was successfully treated with transcatheter arterial embolization (TAE).

\section{Case Report}

A 42-year-old woman was admitted to our hospital for the treatment of liver tumors. Her condition had been complicated by aplastic anemia 33 years ago, and at that time, she was treated with anabolic steroids. She did not get the opportunity to receive HSC transplantation. She was ultimately diagnosed with FA based on the findings of mitomycin C-induced chromosomal breakage analysis in lymphocyte cultures 8 years ago. In the same year, she developed laryngeal cancer and received total laryngectomy. Three months prior to admission to our hospital, she developed multiple pyogenic abscesses in pelvic muscles. Although she was successfully treated with the systemic administration of antibiotics, multiple liver tumors were detected.

On admission, she exhibited a short stature $(143.1 \mathrm{~cm})$ and systematic pigmentation of skin. She has no family history of inherited disorders. Blood count tests showed severe pancytopenia. White blood cell count, hemoglobin concentration, and number of platelets were $400 / \mu \mathrm{L}, 7.3 \mathrm{~g} / \mathrm{dL}$, and 3,000/ $\mu \mathrm{L}$, respectively. Serum levels of aspartate transaminase and alanine transaminase were within their normal ranges (Table 1). However, serum levels of alkaline phosphatase and $\gamma$-glutamyltranspeptidase was elevated (842 and $486 \mathrm{U} / \mathrm{L}$, respectively). Both hepatitis B surface antigen and hepatitis $C$ virus antibody were negative. The levels of $\alpha$-fetoprotein and des- $\gamma$-carboxy prothrombin were $109.6 \mathrm{ng} / \mathrm{mL}$ and 21,377 $\mathrm{mAU} / \mathrm{mL}$, respectively. The patient's Child-Pugh score was 5 (class A).

Contrast-enhanced computed tomography (CT) demonstrated multiple hypervascular tumors in the right hepatic lobe (Fig. 1). The diameter of the main tumor was approximately $90 \mathrm{~mm}$. The lesions were clinically determined to be stage III (T3N0M0). Tumor biopsy re- 


\section{Case Reports in \\ Gastroenterology}

Case Rep Gastroenterol 2017;11:29-35

DOI: $10.1159 / 000454710$

(C) 2017 The Author(s). Published by S. Karger AG, Base www.karger.com/crg

Takahashi et al.: Successful Treatment of Hepatocellular Carcinoma Complicated by Fanconi Anemia

vealed that the tumor comprised of moderately differentiated HCC (Fig. 2a). Nontumor tissue showed scarce inflammation and fibrosis, although iron deposition was observed in hepatocytes (Fig. 2b). In view of the tumor stage and liver function, hepatic resection or transcatheter arterial chemoembolization (TACE) was recommended according to the guidelines for HCC treatment proposed by the Japan Society of Hepatology [7]. However, taking into consideration severe pancytopenia, the treatment approach appeared not to be suitable. We obtained informed consent before treatment and conducted TAE, but not TACE. Concordant with the findings of contrast-enhanced CT, these tumors demonstrated enhancement on CT hepatic angiography and perfusion defect on CT during arterial portography. Lipiodol-CT after TAE exhibited lipiodol deposition in the tumors (Fig. 3). To reduce the risk of complications, both platelet transfusion and intravenous administration of antibiotics were performed prior to TAE. Because she exhibited persistent fever after TAE, the administration of antibiotics was continued. She was eventually discharged 35 days after TAE.

\section{Discussion}

FA, which was first reported in 1927, is a bone marrow failure syndrome characterized by progressive lethal pancytopenia and skeletal abnormalities [8]. FA is attributed to chromosomal instability, and 19 genes responsible for FA have been identified to date $[9,10]$. Although FANCB gene represents an X-linked deleterious mutation in FA complementation group $B$, the remaining FA-associated gene aberrations are autosomally inherited recessive mutations. The incidence of aplastic anemia is $80 \%$ in FA patients aged $\leq 10$ years and $90 \%$ in FA patients aged $\leq 40$ years [11]. The patient in the present case developed pancytopenia when she was 9 years old.

One of the most significant clinical features of FA is FA-associated malignancy. Hematological malignancies are frequently observed in patients with FA, and the incidence of this phenomenon increases with age. Leukemia or myelodysplastic syndrome develops in 30\% of FA patients aged $\leq 30$ years [12]. Although these data suggest that patients with FA should undergo HSC transplantation during childhood, the outcomes associated with this approach have been less than favorable. It has recently been reported that HSC transplantation with a conditioning regimen that includes fludarabine is associated with a favorable survival [13]. In the present case, the patient did not get the opportunity to receive HSC transplantation, and she received blood transfusion and anabolic hormone therapies. Of importance, nonhematological malignancies in FA patients are also associated with a morbidity rate of $25-30 \%$. Squamous cell carcinomas of the head and neck and gynecological malignancies are among the most frequently observed types of cancer in this context [14]. FA in the present case study was complicated by laryngeal cancer, and the patient had previously undergone a total laryngectomy. Because the risk of solid tumor development remains high even in FA patients treated with HSC transplantation, careful attention is required.

It has been reported that the incidence of HCC complicated by FA is $46 \%$ by age 50 [5]. However, there are few reports describing an effective therapeutic intervention for such cases. Hepatic resection and liver transplantation from a compatible donor is an approach reported $[15,16]$ for patients with juvenile-onset FA presenting with relatively mild pancytopenia, a condition that may be considered advantageous. Considering that the success of 
radical treatment in treating HCC in patients with FA is often limited by the severity of pancytopenia, FA-related HCC is associated with a poor prognosis. In the present case, the patient presented with severe pancytopenia; therefore, neither surgery nor administration of anticancer drugs was feasible treatment options. After further consideration, replacement therapy and intravenous antibiotics were administered, and TAE was conducted to control the tumors.

In cases of aplastic anemia, including patients with FA, long-term treatment with anabolic steroids and replacement therapy with blood components is commonly implemented. However, this approach requires extreme caution because of the association of anabolic steroid hormone therapy with iron deposition and hepatocarcinogenesis $[17,18]$. The patient in this report presented with iron deposition resulting from transfusion dependency and long-term treatment with anabolic steroid hormones and immunosuppressants. Iron deposition was suspected to be a contributing factor to the development of HCC. Taken together, it is necessary to pay attention to HCC development in such cases.

In conclusion, this is a first report which documents a case of HCC complicated by FA wherein the patient was successfully treated with TAE. The therapeutic approach against $\mathrm{HCC}$ is usually determined based on the tumor stage and hepatic reserve function. In cases of HCC complicated by FA, the selection of the appropriate therapeutic strategy should be based on a comprehensive evaluation that includes the assessment of the severity of pancytopenia, performance status, and other relevant variables.

\section{Statement of Ethics}

The authors have no ethical conflicts to disclose.

\section{Disclosure Statement}

The authors declare no conflict of interest.

\section{References}

Tischkowitz MD, Hodgson SV: Fanconi anemia. J Med Genet 2003;40:1-10.

Duxin JP, Walter JC: What is the DNA repair defect underlying Fanconi anemia? Curr Opin Cell Biol 2015;37:49-60.

3 Kee Y, D'Andrea AD: Molecular pathogenesis and clinical management of Fanconi anemia. J Clin Invest 2012;122:3799-3806.

4 Ayas M, Saber W, Davies SM, et al: Allogeneic hematopoietic cell transplantation for fanconi anemia in patients with pretransplantation cytogenetic abnormalities, myelodysplastic syndrome, or acute leukemia. J Clin Oncol 2013;31:1669-1676.

Alter BP: Cancer in Fanconi anemia, 1927-2001. Cancer 2003;97:425-440.

6 Rosenberg PS, Greene MH, Alter BP: Cancer incidence in persons with Fanconi anemia. Blood 2003;101:822-826.

7 Kokudo N, Hasegawa K, Akahane M, et al: Evidence-Based Clinical Practice Guidelines for Hepatocellular Carcinoma: The Japan Society of Hepatology 2013 update (3rd JSH-HCC Guidelines). Hepatol Res 2015;45:123-127. 


\section{Case Reports in Gastroenterology}

Takahashi et al.: Successful Treatment of Hepatocellular Carcinoma Complicated by Fanconi Anemia

Fanconi G: Familiare infantile perniziosaartige Anamie (pernizioses Blutbild und Konstitution). Jahrb Kinderheilkd 1927;117:257-280.

-9 Sasaki MS, Tonomura A: A high susceptibility of Fanconi's anemia to chromosome breakage by DNA crosslinking agents. Cancer Res 1973;33:1829-1836.

10 Dong H, Nebert DW, Bruford EA, et al: Update of the human and mouse Fanconi anemia genes. Hum Genomics 2015;9:32.

11 Kulter DI, Singh B, Satagopan J, et al: A 20-year perspective on the International Fanconi Anemia Registry. Blood 2003;101:1249-1256.

12

13 Green AM, Kupfer GM: Fanconi anemia. Hematol Oncol Clin North Am 2009;23:193-214. Dufour C, Svahn J: Fanconi anaemia: new strategies. Bone Marrow Transplant 2008;41:S90-S95.

$>14$ patients with Fanconi anemia. Arch Otolaryngol Head Neck Surg 2003;129:106-112.

15 Ozenne V, Paradis V, Vullierme MP, et al: Liver tumours in patients with Fanconi anaemia: a report of three cases. Eur J Gastroenterol Hepatol 2008;20:1036-1039.

-16 Colle I, Laureys G, Raevens S, et al: Living related liver transplantation in an adult patient with hepatocellular adenoma and carcinoma 13 years after bone marrow transplantation for Fanconi anemia: a case report. Hepatol Res 2013;43:991-998.

17 Mancuso A: Hepatocellular carcinoma in thalassemia: a critical review. World J Hepatol 2010;2:171174.

18 Kosaka A, Takahashi H, Yajima Y, et al: Hepatocellular carcinoma associated with anabolic steroid therapy: report of a case and review of the Japanese literature. J Gastroenterol 1996;31:450-454.
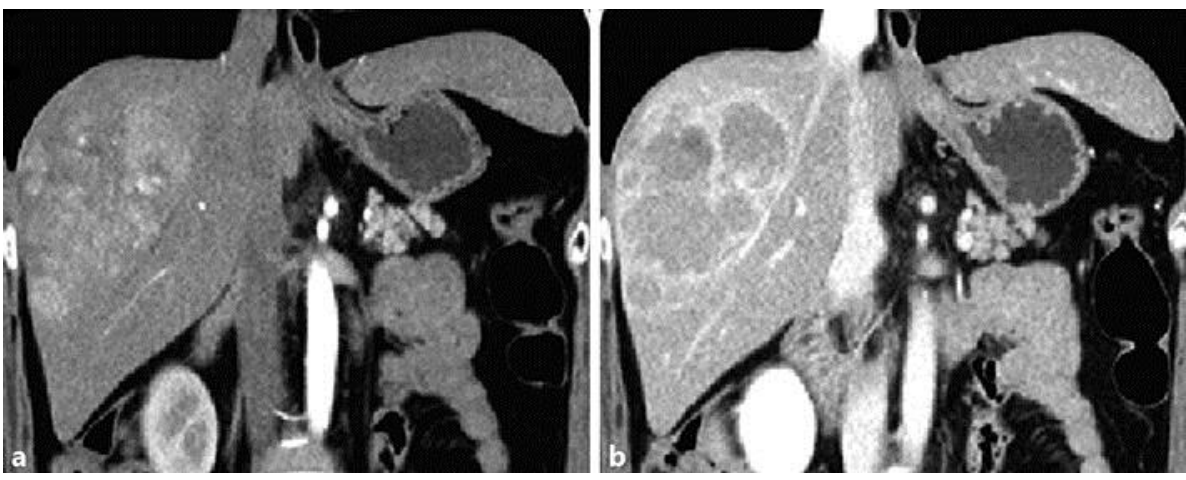

Fig. 1. Contrast-enhanced CT findings. a The tumors in the right hepatic lobe showed enhancement in the arterial phase. $\mathbf{b}$ These lesions showed washout in the equivalent phase. 


\begin{tabular}{ll|l} 
Case Reports in & \multicolumn{2}{c}{ Case Rep Gastroenterol 2017;11:29-35 } \\
\cline { 2 - 3 } Gastroenterology & DOI 10.1159/000454710 & $\begin{array}{l}\text { @ 2017 The Author(s). Published by S. Karger AG, Basel } \\
\text { www.karger.com/crg }\end{array}$ \\
\cline { 2 - 3 } &
\end{tabular}

Takahashi et al.: Successful Treatment of Hepatocellular Carcinoma Complicated by Fanconi Anemia
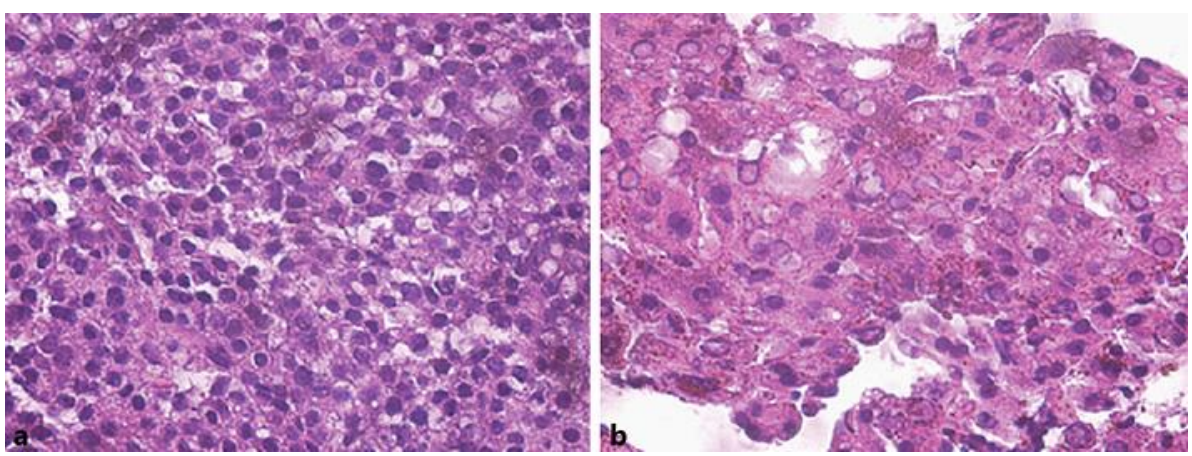

Fig. 2. The pathological findings of the liver biopsy specimen. a The tumor was composed of moderately differentiated HCC. $\mathbf{b}$ Iron deposition in hepatocytes was observed in nontumor tissue. HE. $\times 400$.

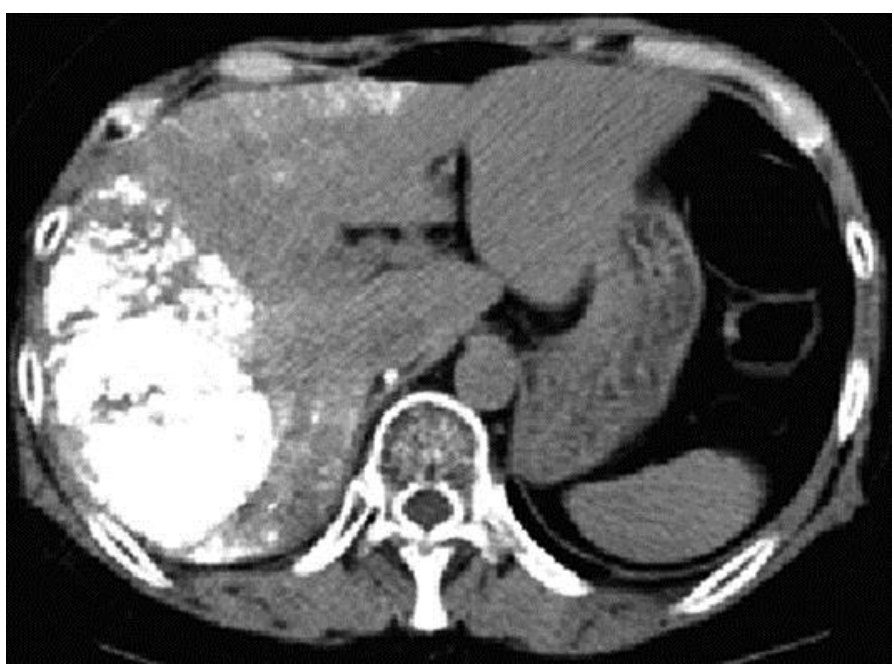

Fig. 3. Findings of lipiodol-CT. CT conducted after TAE showed lipiodol accumulation in the tumors. 
Takahashi et al:: Successful Treatment of Hepatocellular Carcinoma Complicated by

Fanconi Anemia

Table 1. Laboratory data on admission

\begin{tabular}{ll} 
Blood cell count & \\
WBC & $400 / \mu \mathrm{L}$ \\
RBC & $2.53 \times 10^{4} / \mu \mathrm{L}$ \\
$\mathrm{Hb}$ & $7.3 \mathrm{~g} / \mathrm{dL}$ \\
$\mathrm{Ht}$ & $20.5 \%$ \\
$\mathrm{Plt}$ & $0.3 \times 10^{4} / \mu \mathrm{L}$ \\
\hline Coagulation & \\
PT-INR & 1.06 \\
\hline Blood chemistry & \\
TP & $5.9 \mathrm{~g} / \mathrm{dL}$ \\
Alb & $3.6 \mathrm{~g} / \mathrm{dL}$ \\
T-Bil & $0.5 \mathrm{mg} / \mathrm{dL}$ \\
AST & $29 \mathrm{IU} / \mathrm{L}$ \\
ALT & $24 \mathrm{IU} / \mathrm{L}$ \\
LDH & $189 \mathrm{IU} / \mathrm{L}$ \\
ALP & $842 \mathrm{IU} / \mathrm{L}$ \\
$\gamma$-GTP & $486 \mathrm{IU} / \mathrm{L}$ \\
BUN & $10 \mathrm{mg} / \mathrm{dL}$ \\
Cre & $0.49 \mathrm{mg} / \mathrm{dL}$ \\
Fe & $247 \mu \mathrm{dL}$ \\
\hline Serology & \\
CRP & \\
HBsAg & $2.5 \mathrm{mg} / \mathrm{dL}$ \\
HCV-Ab & - \\
HIV-Ab & - \\
Tumor markers & \\
AFP & \\
AFP-L3 & \\
DCP & \\
Ferritin & \\
\hline & \\
\hline & \\
\hline
\end{tabular}

